\title{
Research on learning experiences and teaching strategies of Blackboard system

\author{
Li ZHENG ${ }^{1, a}$, Yinghua NIU ${ }^{2, b}$
}

\author{
${ }^{1}$ Department of E-Business, Business College of Beijing Union University, Beijing, P.R.China \\ ${ }^{2}$ Educational Administration, Business College of Beijing Union University, Beijing, P.R.China \\ ali.zheng@buu.edu.cn, byinghua.niu@buu.edu.cn
}

Keywords: Blackboard system; learning experience; teaching strategy; questionnaire survey

\begin{abstract}
Taking the students' learning experiences and applications of Blackboard system as the research perspective, a typical case study of a local university was carried out. This thesis analyzes the students' perception and experiences of the Blackboard system performance, resources sharing, collaborative learning and evaluation feedback. At the end of the paper, the corresponding teaching strategies and suggestions are put forward so as to provide references and helps for the teachers. The purpose is to make teachers become students’ learning leader, facilitator and helper.
\end{abstract}

\section{Introduction}

In China, the research on education informationization, information technology and curriculum integration was widely carried out. Some famous scholars such as Guonong NAN and Kekang HE made an in-depth theoretical and practical research on the development of educational informatization[1-2]. Ronghuai HUANG, Shengquan YU and other scholars have achieved fruitful research results to promote education reform via information technology. Their research areas include new concepts and new technologies such as mobile learning, smart learning, smart campus, cloud technology and so on [3-4]. Other researches also include the study of modern distance education, the research on the application of modern educational technology and the construction of information resources.

In China, the research of Blackboard network teaching platform can be traced back to 2005. Feng LU studied the collaborative learning based on the Blackboard [5]. Since then, the research of Blackboard is increasing. The researches mainly focus on the mixed teaching mode supported by Blackboard platform [6], cooperative learning through Blackboard [7], study effect evaluation based on Blackboard [8] and so on. But in the process of literature research, we found that it is weak in the area of students' learning experiences study based on the Blackboard. This is obviously a very important aspect in the application of educational technology in current days. So it is clear that a further, specifically and in-depth study is needed. We hope to understand the learning experience of students in the application of Blackboard through a typical case study, explore the existed problems, and provide some helpful suggestions for teachers to adjust their teaching strategies and standardize their network course construction behaviors.

\section{Research design}

In order to have a more in-depth understanding of the students' application behavior and learning experience of Blackboard, grasp their learning needs, the group adopted questionnaire survey to collect data and carry out the research. 


\section{Research object}

The research object is the students from Business College of Beijing Union University. All of the students have the experience of using the Blackboard platform for learning, so they are quite familiar with the functions and using methods of the system. The total distributed number of questionnaire was 100 and 94 were completed, the recovery rate was 94 percent. In the process of data collection and collation, 7 invalid questionnaires were excluded, and 87 valid questionnaires were obtained, the effective rate was 92.6 percent.

\section{Research contents}

Based on the four basic functions, namely the content resources management, online communication, assessment management and system management, and referred to a large number of literature data, the research questionnaire was preliminary designed. After a thorough discussion of some relevant teacher, research personnel and related experts, the contents of the questionnaire were finally determined. The questionnaire was divided into two parts: the first part is the natural information of the respondents, including gender, grade and so on; the second part is the respondents' perception, experience and future expectations of their Blackboard application.

We hope to find out the objective problems in the students' Blackboard application, experience, and reflection, so as to provide references for teachers to adjust their teaching strategies.

\section{Result analysis}

In the questionnaire, in addition to several individual questions, we adopted Likert scale to test students' perception, experience and etc. on their Blackboard application. 1, 2, 3, 4, 5 was used to represent five levels of "total agreement", "agree", "not sure", "do not agree", "totally disagree" respectively. In addition, this questionnaire adopted single choices only. Spss13.0 was used to collect data and carry out the study. Below is the specific and detailed situation analysis.

\section{System performance}

The experiences of students on the performance of Blackboard system mainly include the following aspects: (1) Is it smooth when you log in? (2) Is the curriculum interface well-organized? (3) Are the functions provided by Blackboard rich? (4) Is the navigation clear? (5) Is the link correct? (6) Is it quick to upload and download files? (7) Is the network platform running stable? Therefore, the system performance of the Blackboard was investigated according to these seven aspects. The survey results are shown in Figure 1.

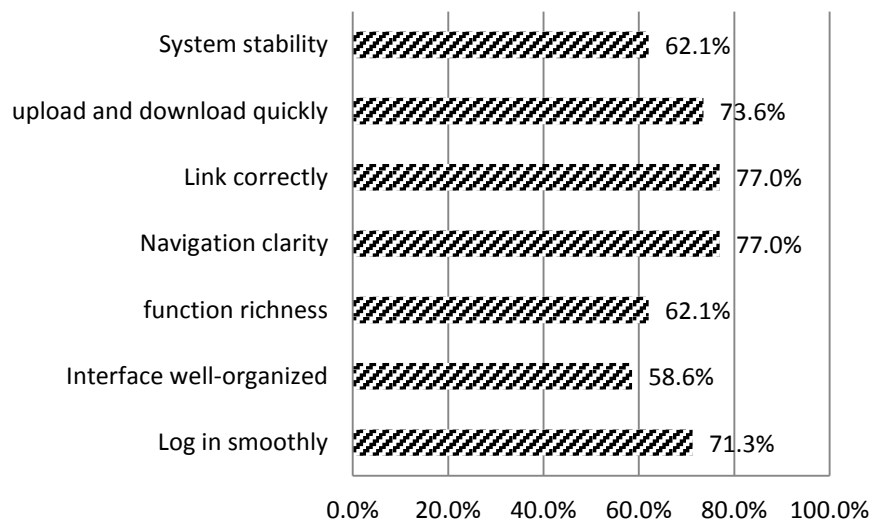

Figure 1 Students experiences on the performance of the Blackboard system 
The results show that: in general, a majority of students' experience of Blackboard system performance is of medium level. Among them, the students expressed their satisfaction to the system navigation and link clarity. But they were not satisfied with the system interface design. The results also show that the Blackboard system is not stable enough, sometimes there will be malfunction, and the system function has not been effectively developed and utilized. All of these problems have affected the enthusiasm and the experience of the students, which need to be further studied and improved.

\section{Resource sharing}

Resource sharing refers to the Blackboard provision of resources and sharing, including resource richness, resource type diversity, update speed, information sharing sufficiency and several other aspects. The questionnaire focuses on these questions to explore the students' perception and experience.

Since we use 1, 2, 3, 4, 5 to represent "completely agree", "agreed", "not sure", "do not agree", "totally disagree", therefore, the smaller the weighted average of the statistical results, the higher the degree of recognition of the respondents. The survey results show that: about the five aspects of providing rich learning resources, content update and the synchronization with course schedule, the accessibility of other Blackboard-based courses, promotion the sharing of information and intelligence, help to students' research study and autonomous learning, and aided to study and review repeatedly after class, in the 87 respondents, the statistical results average values were 2.23, 2.43, 2.17, 2.34, 2.20, and 2.51. The standard deviation is $0.872,0.948,1.163,0.925,0.860$, and 0.938 . The detailed was shown as Table I . This reflects the students' basic attitude and satisfaction on the Blackboard resource sharing. Most of them express their recognition. On the other hand, the standard deviation shows that the survey difference of students is relatively small. The students' perception and experience distribution is much more concentrated.

TABLE I. SURVEY RESULTS ON RESOURCES AND SHARING

\begin{tabular}{|l|c|c|c|}
\hline \multicolumn{1}{|c|}{ Investigation items } & Mean value & $\begin{array}{c}\text { Standard } \\
\text { deviation }\end{array}$ & Respondents \\
\hline $\begin{array}{l}\text { Blackboard system provides a wealth of } \\
\text { learning resources for my study. }\end{array}$ & 2.23 & 0.872 & 0.948 \\
\hline $\begin{array}{l}\text { For most courses, I think the construction and } \\
\text { updating of Blackboard is appropriate with its } \\
\text { schedule. }\end{array}$ & 2.43 & 0.802 & 87 \\
\hline $\begin{array}{l}\text { For most courses, the learning resources } \\
\text { provided by the Blackboard are mainly based } \\
\text { on the content of text type, video, audio and } \\
\text { other information type is less. }\end{array}$ & 2.39 & 1.163 & 87 \\
\hline $\begin{array}{l}\text { I hope to be able to enter other Blackboard- } \\
\text { based courses' websites in the university, read } \\
\text { and learn some useful contents. }\end{array}$ & 2.17 & 0.925 & 87 \\
\hline $\begin{array}{l}\text { The application of Blackboard is more helpful } \\
\text { to share information and intelligence between } \\
\text { teachers and students. }\end{array}$ & 2.34 & 0.860 & 87 \\
\hline $\begin{array}{l}\text { The application of Blackboard is more helpful } \\
\text { for my own study and research. }\end{array}$ & 2.20 & 2.51 & 838 \\
\hline $\begin{array}{l}\text { The application of Blackboard is more } \\
\text { conducive for my repeated learning on } \\
\text { difficulties and key contents of the courses. }\end{array}$ & & & 87 \\
\hline
\end{tabular}

Also it is worthy to say that for most of the curriculum, the learning resources provided by Blackboard is text type contents, video type and audio type data is inadequate. This has affected the students' learning 
experience. The proportion of students holding this view is almost 65.5 percent. In the following random interviews with part of the students, they said that compared with the text type resources, audio type, video type and other forms of curriculum information can improve their learning interest. This reflects the need and desire of the students to study with various types of learning resources.

\section{Communication and cooperation}

The investigation of the communication and cooperation based on the Blackboard system mainly focuses on the following aspects: (1) Whether the teacher has created a good environment for the students' group cooperative learning? (2) Whether the discussion topic set by teachers closely related to learning contents and the actual reality? (3) Whether the teachers' respond, guide and evaluation are quick and timely? (4) Whether the application of Blackboard is more convenient and helpful for students and teachers to communicate with each other in the teaching process?

Results show that about 60 percent of the students think that the applications of Blackboard construct a good environment for their group collaborative learning. It is helpful for them to carry out their learning and communication, resource sharing, and cooperation to complete the task of the course. 63.2 percent of the students approve of the discussion topics set by teachers in the Blackboard. They think these discussion questions can be closely linked to the learning contents, and be able to reflect problems in the real world. So this will help to lead students to think deeply and also to provide the students with a good environment to apply what they have learned to solve practical problems. Most of the students consider that it has very important and practical significance. About the teachers' function and guidance to the discussion, half of the students said Yes, whereas the other half said No. The students have different opinions. In fact, teachers' conduction in the Blackboard indeed exist absence phenomena, the guidance is not always timely, the evaluation and summary is not always effective in the whole process. In addition, 55.2 percent of the students think that the application of Blackboard is more convenient for students and teachers to communicate with each other. But the proportion was significantly lower.

Furthermore, about 60 percent students said that, compared with the problem consultation by on-line communication, they were more inclined to ask the teacher questions in traditional face-to-face way. This should arouse the attention of teachers. The application of Blackboard in teaching is a development and supplement of classroom teaching, but it does not mean that it can replace the teachers' internal and external guidance and instruction to students. The exemplary role of teachers and campus cultural atmosphere of Universities will have a subtle influence on the students. This cannot be achieved only via simple network communication.

\section{Evaluation and feedback}

The evaluation and feedback involved in this study refers to self-inspection, testing, and evaluation via Blackboard, online survey was not included. Statistical results showed that about 77 percent of students often take advantage of the Blackboard to do their homework, practice, testing, and research study. They are eager to find the problems existed in their learning process. 52.9 percent of the students think that for most of the courses, teachers will provide adequate and synchronized testing materials in the Blackboard. But still almost half of the students do not recognize this statement. It is considered that the contents of the online test are few, and they are not updated in time. So it is not conducive for them to understand their real learning situation.

On the other hand, the students are very concerned about and eager to know the real-time display scores, the proportion of students with this idea reached 73.6 percent. At the same time, about 84 percent of the students hope to check up the correct answers and explanations after they have finished their online test. This reflects the students' positive attitudes to monitor their learning situation, discover the problem and improve their learning methods and learning strategies. 
Through the above research we can find that students have strong demand to find out their learning level, evaluate their learning effects by themselves through the Blackboard network platform. From this point of view, teachers should listen carefully to the opinions and suggestions of the students; add new tests, exercises, assignments, and so on in time. At the same time, teachers should provide the students with more detailed and timely feedback to evaluate their homework or test and have targeted guidance, which will help to promote students to produce a better Blackboard network platform application experience, and at last improve their use of Blackboard for learning with great enthusiasm.

\section{Conclusions}

In this paper, a typical case study of a local university students application experiences on Blackboard system was deeply carried out. The paper analyzes four aspects of the system performance, resources sharing, communication, evaluation and feedback, and draws the following conclusions.

Most students have a positive attitude and positive learning experience for the important role of Blackboard, the overall situation of the construction of the system is satisfactory. But many students still hope to further improve. So teachers need to think carefully and put it into action, give more detailed planning and management to the Blackboard-based courses.

For example, teachers can consciously increase the practice and testing contents, and set strict deadline for the students to complete and hand it in through designated way. Meanwhile, teachers should also provide the students with lots of audio type, video type learning resources which are closely related to the course contents so as to further improve the students' learning interests.

In the application of Blackboard platform for learning and collaboration, the results show that lots of students learning are still relatively passive. Therefore, the teachers should pay attention to the teaching process, and guide students actively. For example, set up rich and challenging topics in the discussion board, lead and courage students to participate in the discussion and group collaboration actively, establish autonomous learning and research learning channels, let the excellent students can feel the charm of further exploration, research, promote the formation of their creative thinking. The goal is to make the teachers become the students learning leader, facilitator and helper.

In addition, teachers can make full use of the statistical functions provided by Blackboard itself, often browse and observe the students' learning behavior, browse preference, participation degree and completion with assignments and tests to discover the problems existed in the process of the students' learning, adjust teaching strategies and solve the problems effectively. The purpose is to make teachers become the students learning leader, facilitator and helper.

\section{Acknowledgment}

In this paper, the research was sponsored by the Funding Project for Academic Human Resources Development in Beijing Union University (BPHR2014F03), and the Funding Project for 2014 Reform of Higher Education in Beijing (2014-ms191).

\section{References}

[1] Guonong NAN. New stage of the development of educational informationization in China[J]. EEducation Research. 2011(12): 10-12

[2] Kekang HE. Study of "education information for ten years development plan" [J]. E-Education Research. 2012(12): 19-23 
[3] Ronghuai HUANG et al. Smart Campus: The Developing Trends of Digital Campus [J]. Open Education Research. 2012(8): 12-17

[4] Shengquan YU. Push on two-way integration of technology and education[J]. China Educational Technology. 2012(5): 5-14

[5] Feng LU. Study of Collaborated-Learning Based on Blackboard E-Education Platform[J]. Journal of Jiangsu Radio \& Television University. 2005(6): 38-40

[6] Wentao PAN. The action research on the hybrid teaching mode based on network resources[J]. China Educational Technology. 2006(8): 49-51

[7] Yafei WANG. The application Study of Collaborative Learning in Blackboard[D]. Hebei Normal University. 2011

[8] Bo LUAN, Aiwei SUN. Research on formative assessment model based on BB platform[J]. SoftwareGuide.2011(3):65-67 